\title{
Nutritional Status and Sugary Drinks Consumption in Children from 6 to 9 years
}

\author{
Teresa Santos ${ }^{1}$, Manuel Bicho ${ }^{2,3}$ and Ana Valente ${ }^{1,2 *}$ \\ ${ }^{1}$ Atlântica-Escola Universitária de Ciências Empresariais, Saúde, Tecnologias e Engenharia, Barcarena, Portugal \\ ${ }^{2}$ Laboratório de Genética, Instituto de Saúde Ambiental, Faculdade de Medicina da Universidade de Lisboa, Portugal \\ ${ }^{3}$ Instituto de Investigação Científica Bento da Rocha Cabral, Lisboa, Portugal
}

\begin{abstract}
Introduction: Obesity is considered one of the most serious public health problems today. It has been linked to increased consumption of sugar from food and in particular from sugary drinks. However, the contribution of its consumption to the increased prevalence of overweight in children is still controversial.

Objective: To relate the nutritional status with the frequency of consumption of sugary drinks in children from 6 to 9 years.

Methods: Cross-sectional observational study in 267 children aged 6 to 9 years from four primary schools in Barcarena. Socioeconomic data were obtained by a questionnaire applied to carers. Nutritional status was assessed by BMI according to WHO and CDC criteria. The frequency of consumption of sugary drinks was assessed by a qualitative food frequency questionnaire. The association between nutritional status and the frequency of consumption of sugary drinks was assessed by logistic regression. Statistical significance was considered when $\mathrm{p}<0.05$.
\end{abstract}

Results: According to WHO criteria, 58\% had normal weight, $24 \%$ pre-obesity and 18\% obesity. The results obtained according to the CDC indicated $61.8 \%$ normal weight, $19.5 \%$ pre-obesity and $17.3 \%$ obesity. The prevalence of overweight was higher in boys. Belonging to the consumption class of iced tea, nectar and fruit juice "up to once a week" seems to favor the risk of obesity (OR = 1.95; $\mathrm{p}=0.098)$.

Conclusion: There is a tendency to associate the frequency of consumption of sugary drinks with nutritional status of children, being more likely that they are overweight when they belong to the consumption class of iced tea, nectar and fruit juice "until once a week".

KEYWORDS: Children; Obesity; Sugary drinks

\section{INTRODUCTION}

Obesity is considered one of the most serious public health problems today. The World Health Organization (WHO) has considered it as the $21^{\text {st }}$ century epidemic [1]. The WHO defines obesity as a disease in which excess body fat accumulates to affect health. However, the amount, body distribution and health consequences vary among obese individuals. Their classification

\begin{tabular}{|l|l|} 
Quick Response Code: & $\begin{array}{l}\text { Address for correspondence: Ana Valente, Atlântica - Escola Universitária de } \\
\text { Ciências Empresariais, Saúde, Tecnologias e Engenharia, Portugal }\end{array}$ \\
\cline { 2 - 2 } & $\begin{array}{l}\text { Received: February 25, } 2020 \quad \text { Published: March 16, } 2020 \\
\text { How to cite this article: Teresa S, Manuel B, Ana V. Nutritional Status and Sugary Drinks } \\
\text { Consumption in Children from } 6 \text { to } 9 \text { years. } 2020 \text { - 2(2) OAJBS.ID.000153. } \\
\text { DOI: } 10.38125 / O A J B S .000153\end{array}$ \\
\end{tabular}


in children is difficult as height and body composition change constantly and occur at different times in each child's development. Childhood obesity is estimated to be the predominant pediatric disease worldwide. The main reasons for raising so many concerns in the medical and scientific community are due to its association with the development of other diseases, as well as the strong link between childhood and adolescent obesity and its persistence into adulthood (WHO). [2] report that in the first decade of this century, about $28 \%$ of school age children and $12 \%$ of preschool age children had pre-obesity or obesity in most developed countries. At the beginning of the $21^{\text {st }}$ century, Portugal was one of the countries where overweight was among the highest in Europe, with about $31.5 \%$ of Portuguese children either pre-obese or obese [3].

When compared with other European countries, the same can be observed in the considered countries of southern Europe, Italy [4]. More recent data point to a decrease in the prevalence of obesity in Portugal when compared to previous years $[5,6]$. These results are in line with those obtained in other European countries, such as Denmark and England, where there were trends for decreasing pre-obesity and obesity $[7,8]$. Several studies relate childhood obesity to the growth in dietary sugar consumption, particularly sugary beverages (BA) [9]. The WHO admits that the consumption of BA may contribute to the epidemic [10], since the consumption of these beverages increases the total energy intake [11]. There is no consensual definition of the term sugary drinks. The general term includes, in this range of beverages, soft drinks (carbonated or non-carbonated soft drinks), fruit juices, lemonades and added sugar tea [12]. Some authors also include energy and sports drinks in this definition [13-15]. Beverages like 100\% juice are not included in soft drinks definition and may be part of a heathy diet but their consumption should be limit. There are also other drinks that are not recommended as part of a healthy diet in early childhood (plant milks/non-dairy beverages, flavoured milk, toddler milk, sugar-sweetened beverages, beverages with LCS, and caffeinated beverages) [16]. Although milk and alternative milk drinks have other nutrients that differentiate them from other sugary drinks, the addition of sugar increases their energy value without obtaining nutritional benefits.

A 2012 study in nine European countries assessed adolescent beverage comsuption as drinking water, followed by sugary drinks and fruit juices [17]. In the pediatric population, the increase in the intake of these drinks has been predominant in children aged 6 to 11 years, which puts them at greater risk for the future development of metabolic or cardiovascular diseases [18]. Thus, there is no consensus on the contribution of the consumption of sugary drinks to increase the prevalence of pre-obesity and obesity in children. Studies suggest a correlation between consumption of these drinks and long-term weight gain [19], while others find no association [20]. Although the prevalence of overweight children in Portugal has been decreasing Graça [6], obesity remains a public health problem that needs to be addressed. Information on the consumption of sugary drinks in school-age children remains inadequate and its relationship with nutritional status needs to be more explored in Portugal $[21,22]$. The present work aims to relate the nutritional status with the frequency of consumption of sugary drinks in children from 6 to 9 years.

\section{METHODOLOGY}

\section{Study Design}

A cross-sectional observational epidemiological study of 267 children aged 6 to 9 years attending one of the four primary schools
(Leceia, Queluz de Baixo, Tercena and Velejas) in the parish from Barcarena.

\section{Ethical Considerations}

All research work has been developed in accordance with the considerations contained in the Declaration of Helsinki [23]. Initially, the principals of the various school groupings were contacted by letter explaining the study and requesting permission to conduct it. Subsequently, upon their consent, the school coordinators were contacted through which all the caretakers of the randomly selected pupils were sent detailed information of the project and informed consent to allow their children participation. Data collection was performed only after confirming the signature of informed and informed consent of the child's guardians and the child's consent at the time of the anthropometric assessment.

\section{Socioeconomic Data}

They were obtained through the development and application of a closed response self-completion questionnaire sent to the caregivers of the participating children. With the application of this questionnaire it was possible to obtain information regarding parents' education, as well as the monthly income of the household.

\section{Anthropometric Data}

Anthropometric measurements were performed according to international standard procedures WHO and calibrated equipment. The anthropometric data measured included weight and height. Weight was measured in kilograms to an accuracy of $100 \mathrm{~g}$. Height was recorded to an accuracy of $1 \mathrm{~mm}$ using a stadiometer. To assess nutritional status, BMI was calculated according to WHO criteria. BMI was assessed using the WHO growth curves for children aged 5 to 19 years [24]. The WHO criterion defining pre-obesity was used when the BMI to age ratio $\geq+1$ standard deviation (SD) and $<+2$ $\mathrm{SD}$ from the baseline median, which is a percentile value of at least 85 and a BMI $\geq 25 \mathrm{~kg} / \mathrm{m}^{2}$ in adulthood. Using the same criterion, obesity was defined as BMI ratio values for age $\geq+2 \mathrm{DP}$ of the reference median, equivalent to a percentile value of at least 97 and a BMI of $\geq 30 \mathrm{~kg} / \mathrm{m}^{2}$ at 19 years. In turn, underweight was defined for BMI ratio values for age $\leq-2 \mathrm{DP}$ of the reference median [25]. The assessment of nutritional status was also performed by calculating BMI according to the CDC criteria, using the growth curves for age and the corresponding percentiles. Pre-obesity was defined when the percentile value was equivalent to the 85 th percentile to below the $95^{\text {th }}$ percentile; obesity was defined when the percentile value was at least 95; and low weight was defined when the percentile value was lower than the $5^{\text {th }}$ percentile [25].

\section{Food Data}

The collection of data on the frequency of consumption of sugary drinks was performed by applying a self-filling nonquantitative food frequency questionnaire. The questionnaire was sent to the parents of the participating children. In order to prepare the questionnaire, information was collected on all sugary drinks available for sale in four large areas in the municipality of Oeiras. Subsequently, the information was grouped to include sugary drinks with similar characteristics. The frequency of consumption intervals were chosen based on the food consumption frequency questionnaire validated for the Portuguese population, available for consultation http://higiene.med.up.pt/freq.php.

\section{Statistical Analysis}

The statistical analysis was performed using the software PSPP, version 0.8.5-gdaa1fe, from the Free Software Foundation. The 
results are expressed as mean $\pm \mathrm{SD}$ and as number and percentage. Qualitative variables were compared using the Chi-square test. To assess the consumption of sugary drinks, a hierarchical group analysis was performed, using 3 groups, the aggregation method was the link between groups and the measure used was the Euclidean distance squared. As a measure of association between nutritional status and belonging to one of the groups of consumption of sugary drinks, we estimated the Odds ratio (OR), through a logistic regression. For all tests, statistical significance was considered when $\mathrm{p}<0.05$.

\section{RESULTS}

Table 1: General characteristics of the children in the study.

\begin{tabular}{|c|c|}
\hline Characteristics & Children (n=267) \\
\hline Age (years) & $7.46 \pm 1.14$ \\
\hline School & $37(14.0)$ \\
\hline Leceia & $104(39.0)$ \\
\hline Queluz de Baixo & $70(26.0)$ \\
\hline Tercena & $56(21.0)$ \\
\hline Valejas & $120(45.0)$ \\
\hline Sex & $147(55.0)$ \\
\hline Girls & \\
\hline Boys & \\
\hline
\end{tabular}

Note: The results are expressed as average or as number of individuals (percentage).

The Table 1 shows the general characteristics of the study population. The children's average age was 7 years and 5 months $(7.46 \pm 1.14$ years). With regard to school distribution, $14 \%$ of children attended the school in Leceia, 21\% Valejas, 26\% Tercena and 39\% Queluz de Baixo. Finally, 45\% of children were girls and $55 \%$ boys.

The children's nutritional status, assessed according to the WHO and CDC criteria, is described in Table 2. According to the WHO criteria, no child was underweight, $58 \%$ had normal weight, $24 \%$ pre-obesity and $18 \%$ obesity, with the prevalence of preobesity and obesity being higher in boys than in girls. As for the CDC criteria, $1.5 \%$ of children were underweight, $61.8 \%$ normal weight, $19.5 \%$ pre-obesity and $17.3 \%$ obesity. It was observed that the prevalence of pre-obesity and obesity were higher in boys and that, in relation to low weight, they were mostly girls. Although there are differences between the two sexes, they are not statistically relevant ( $p>0.05)$. The Table 3 shows the socioeconomic data of the children by school attended. There is a relative balance with regard to factors of educational qualifications of parents and household income in Queluz, Tercena and Valejas. The Leceia school has the parents with lowest education qualifications and monthly income. The school of Tercena has the highest percentage of mothers with higher education level (58.8\%), while the school with the lowest percentage is Leceia (18.9\%). The same happens when we look at the father's education level. The highest percentage belongs to the school of Tercena (42.6\%) and the lowest to Leceia $(15.2 \%)$. An analysis of family income shows that the Queluz school stands out as the one in which parents have higher incomes, which contradicts the data regarding the level of education of parents who have higher values both in Tercena and in Valejas. As for the households with the lowest income, Leceia has the lowest values. The first two levels reach $58.8 \%$. A much higher percentage than Queluz (19.6\%), Tercena (28.8\%) and Valejas (28.0\%). Despite the differences observed between schools in relation to these factors, only in the monthly income was a statistically significant difference $(\mathrm{p}=0.001)$.

Table 2: Assessment of children's nutritional status.

\begin{tabular}{|c|c|c|c|}
\hline \multirow{2}{*}{ Nutritional status } & \multicolumn{3}{|c|}{ Children } \\
\cline { 2 - 4 } & Girls & Boys & Total \\
\cline { 2 - 4 } & (n=120) & (n=147) & (n = 267) \\
\hline Low weight & & & \\
\hline CDC & $3(1.10)$ & $1(0.40)$ & $4(1.50)$ \\
\hline WHO & $0(0.00)$ & $0(0.00)$ & $0(0.00)$ \\
\hline Normal weight & & & \\
\hline CDC & $71(26.6)$ & $94(35.2)$ & $165(61.8)$ \\
\hline WHO & $70(26.2)$ & $85(31.8)$ & $155(58.0)$ \\
\hline Pre-obesity & & & \\
\hline CDC & $25(9.40)$ & $27(10.1)$ & $52(19.5)$ \\
\hline WHO & $29(10.9)$ & $35(13.1)$ & $64(24.0)$ \\
\hline Obesity & & & \\
\hline CDC & $21(7.90)$ & $25(9.40)$ & $46(17.3)$ \\
\hline WHO & $21(7.90)$ & $27(10.1)$ & $48(18.0)$ \\
\hline CDC $)$ & & \\
\hline & & & \\
\hline
\end{tabular}

Note: The results are expressed in number of individuals (percentage). CDC, Center for Disease and Control Prevention; WHO, World Health Organization.

Table 4 it shows the association between nutritional status and the socioeconomic data of the children in the sample. With regard to the mother's education qualification, nutritional status nutritional status and educational attainment, the highest percentage in children with normal weight is the higher education degree $(24.1 \%)$ while in overweight children it is the secondary education degree $(16,3 \%)$, followed by the higher education degree (16.0\%). Despite the observed differences, these are not statistically significant ( $\mathrm{p}=0.875 ; \mathrm{OR}=0.978)$. Regarding the association between the father's educational attainment and nutritional status, children with normal weight have the highest percentage in parents with a higher education degree $(21.2 \%)$ while in overweight children the secondary education degree $(15.9 \%)$ is the most prevalent, followed by basic education (14.7\%) and lastly higher education (9.8\%). However, the differences are not statistically significant ( $p$ $=0.161 ; \mathrm{OR}=1.81$ ). The monthly household income of this sample is more evident in the strata with an average income above 1000 - $2000 €$, followed by the highest income> $2000 €$. The highest percentage in children with normal weight is a monthly income between $1000-2000 €(23.0 \%)$ and the lowest can be found in income $<1000 €(16.2 \%)$. As for overweight children, the highest percentage is also in income $1000-2000 €$ but the lowest becomes in income $>2000 €(10.6 \%)$. The difference in results, however, is not statistically significant $(\mathrm{p}=0.426$; $\mathrm{OR}=1.53$ ). 
Table 3: Socio-economic data of the children according to the school attended.

\begin{tabular}{|c|c|c|c|c|c|}
\hline \multirow{2}{*}{ Socio-Economic Data } & \multicolumn{5}{|c|}{ School } \\
\hline & Leceia & Queluz & Tercena & Valejas & Total \\
\hline \multicolumn{6}{|c|}{ Mother's Educational Qualifications } \\
\hline $1^{\text {st }}$ Cycle EB & $0(0.00)$ & $1(1.01)$ & $1(1.54)$ & $0(0.00)$ & $2(0.77)$ \\
\hline $2^{\text {nd }}$ EB Cycle & $4(10.8)$ & $7(7.10)$ & $1(1.54)$ & $3(5.36)$ & $15(5.83)$ \\
\hline $3^{\text {rd }}$ EB Cycle & $10(27.0)$ & $9(9.10)$ & $11(16.9)$ & $9(16.1)$ & $39(15.2)$ \\
\hline High school & $16(43.3)$ & $42(42.4)$ & $19(29.3)$ & $21(37.5)$ & $98(38.1)$ \\
\hline University education & 7 (18.9) & $40(40.4)$ & $33(50.8)$ & $23(41.1)$ & $103(40.1)$ \\
\hline Total & $37(12.2)$ & $99(38.5)$ & $65(25.5)$ & $56(21.8)$ & 257 \\
\hline \multicolumn{6}{|c|}{ Literary Qualifications of the Father } \\
\hline $1^{\text {st }}$ Cycle EB & $1(3.00)$ & $2(2.00)$ & $2(3.30)$ & $0(0.00)$ & $5(2.10)$ \\
\hline $2^{\text {nd }}$ EB Cycle & $4(12.1)$ & $8(8.10)$ & $3(4.90)$ & $2(3.90)$ & $17(6.90)$ \\
\hline $3^{\text {rd }}$ EB Cycle & $11(33.3)$ & $22(22.2)$ & $13(21.3)$ & $11(21.1)$ & $57(23.3)$ \\
\hline High school & $12(36.4)$ & $41(41.4)$ & $17(27.9)$ & $20(38.5)$ & $90(36.7)$ \\
\hline University education & $5(15.2)$ & $26(26.3)$ & $26(42.6)$ & $19(36.5)$ & $76(31.0)$ \\
\hline Total & $33(13.5)$ & $99(40.4)$ & $61(24.9)$ & $52(21.2)$ & 245 \\
\hline \multicolumn{6}{|c|}{ Monthly Income } \\
\hline$<500 €$ & 4 (11.8) & $0(0.00)$ & 7 (11.9) & $2(4.00)$ & $13(5.60)$ \\
\hline $500-1000 €$ & $16(47.0)$ & $18(19.6)$ & $10(16.9)$ & $12(24.0)$ & $56(23.8)$ \\
\hline $1000-2000 €$ & $6(17.7)$ & $43(46.7)$ & $25(42.4)$ & $20(40.0)$ & $94(40.0)$ \\
\hline$>2000 €$ & $8(23.5)$ & 31 (33.7) & $17(28.8)$ & $16(32.0)$ & $72(30.6)$ \\
\hline Total & $34(14.5)$ & $92(39.1)$ & $59(25.1)$ & $50(21.3)$ & 235 \\
\hline
\end{tabular}

Note: The results are expressed in number of individuals (percentage). EB, Basic Education.

Table 4: Association between nutritional status and socioeconomic data.

\begin{tabular}{|c|c|c|}
\hline \multirow{2}{*}{ Socio-Economic Data } & \multicolumn{2}{|c|}{ Nutritional Status } \\
\hline & Normal Weight & Over Weight \\
\hline \multicolumn{3}{|c|}{ Mother's Educational Qualifications } \\
\hline Basic education & $34(13.2)$ & $22(8.60)$ \\
\hline High school & $56(21.8)$ & $42(16.3)$ \\
\hline University education & $62(24.1)$ & $41(16.0)$ \\
\hline Total & $152(59.1)$ & $105(40.9)$ \\
\hline \multicolumn{3}{|c|}{ Father's Educational Qualifications } \\
\hline Basic education & $43(17.6)$ & $36(14.7)$ \\
\hline High school & $51(20.8)$ & $39(15.9)$ \\
\hline University education & $52(21.2)$ & $24(9.80)$ \\
\hline Total & $146(59.6)$ & $99(40.4)$ \\
\hline \multicolumn{3}{|c|}{ Monthly Income } \\
\hline$<1000 €$ & $38(16.2)$ & $31(13.2)$ \\
\hline $1000-2000 €$ & $54(23.0)$ & $40(17.0)$ \\
\hline$>2000 €$ & $47(20.0)$ & $25(10.6)$ \\
\hline Total & $139(59.2)$ & $96(40.8)$ \\
\hline
\end{tabular}

Note: The results are expressed in number of individuals (percentage). Overweight (includes pre-obesity and obesity). 
Table 5: Frequency of consumption of sugary drinks.

\begin{tabular}{|c|c|c|c|}
\hline \multirow{2}{*}{ Sugary Drinks } & \multicolumn{3}{|c|}{ Consumption Frequency } \\
\cline { 2 - 4 } & Never or <1 time per Month & Up to 1 time per Week & More than once a Week \\
\hline Coke or Pepsi & $175(65.5)$ & $70(26.2)$ & $11(4.10)$ \\
\hline Iced Tea & $85(31.8)$ & $102(38.2)$ & $71(26.6)$ \\
\hline Gaseous & $230(86.1)$ & $3(1.10)$ \\
\hline Soda with gas & $210(78.7)$ & $36(13.5)$ & $7(2.60)$ \\
\hline Refrigerant without gas & $166(62.2)$ & $50(18.7)$ & $36(13.5)$ \\
\hline Energetic & $247(92.5)$ & - & - \\
\hline Sporty & $238(89.1)$ & - & $1(0.40)$ \\
\hline Fruit concentrate & $198(74.2)$ & $35(13.1)$ & $12(4.50)$ \\
\hline Fruit nectar & $79(29.6)$ & $116(43.5)$ & $54(20.2)$ \\
\hline Fruit juice & $86(32.2)$ & $115(43.1)$ & $48(18.0)$ \\
\hline Powdered refreshment & $226(84.6)$ & $8(3.00)$ & $9(3.40)$ \\
\hline Milk with chocolate & $55(20.6)$ & $59(22.1)$ & $10(3.80)$ \\
\hline Alternative to milk & $223(83.5)$ & & $141(52.8)$ \\
\hline
\end{tabular}

Note: The results are expressed as number of individuals (percentage).

The Table 5, referring to the frequency of consumption of sugary drinks, reveals a very high frequency of consumption of chocolate milk and iced tea. With regard to the consumption of energy or sports drinks, the value is residual with only one child admitting consumption. The results for nectars and fruit juices show similar numbers in terms of frequency, recognizing that "up to 1 time a week" and "more than 1 time a week" are practiced by more than $60 \%$ of children. As for drinks such as carbonated, carbonated or non-carbonated soft drinks, Coca-Cola or Pepsi, fruit concentrate, powdered soft drinks and drinks alternative to milk, the frequency appears as low. In relation to drinks such as iced tea and chocolate milk, they are evenly distributed in terms of frequency of consumption in the three groups presented. The big difference is that iced tea has a percentage of $26.6 \%$ of consumption "more than once a week", compared with the chocolate milk with $52.8 \%$ for the same frequency of consumption. To associate each sugary drink with a specific consumption frequency, a hierarchical group analysis was carried out (Table 6), where the number of classes was three and where the aggregation method was the connection between groups and the measure used was the Euclidean distance squared. Drinks were grouped into classes taking into account children's drinking behavior, with "never less than once a month" in class 1, "up to once a week" in class 2 and "more than once a week" class 3. It was found that the drinks referring to class 1 were Coca-cola or Pepsi, carbonated, soft drinks (with and without gas), energy and sports drink, fruit concentrate, powdered soft drink and drinks alternative to milk. Those that were part of class 2 were iced tea, nectar and fruit juice. Finally, only chocolate milk belonged to class 3 . After the association between each drink and the children's consumption behaviour was made according to frequency, an association was made between their nutritional status and the classes through of a binary logistic regression. Although the results are not statistically significant ( $p>0.005)$, a trend can be observed between belonging to one of the classes and being overweight. As shown in Table 6, belonging to class 1 is associated with a protective effect against excess weight $(\mathrm{OR}=0.40)$ whereas belonging to class 2 has the opposite effect $(\mathrm{OR}=1.95)$. In relation to class 3 , belonging to this class has a non-significant result.
Table 6: Association of excess weight with the frequency of consumption of sugary drinks.

\begin{tabular}{|c|c|c|}
\hline Variable & Odds Ratio & $\mathbf{p}$ \\
\hline Class $1^{*}$ & 0.40 & 0.347 \\
\hline Class $2^{* *}$ & 1.95 & 0.098 \\
\hline Class $3^{* * *}$ & 0.91 & 0.815 \\
\hline
\end{tabular}

Note: *Frequency of consumption "Never or less than once a month" associated with Coca-Cola or Pepsi, carbonated, soft drinks (with and without gas), energy drink, sports drink, fruit concentrate, powdered drink and drinks alternative to milk .

**Frequency of consumption "Up to once a week" associated with iced tea, nectar and fruit juice.

***Frequency of consumption "More than once a week" associated with chocolate milk.

\section{DISCUSSION}

The primary school phase is a time of growth in the emotional, cognitive and social areas. In this phase, children gain greater autonomy, become more responsible, acquire new routines and habits. In addition, it is a period of growth prior to puberty, which is essential to predict overweight in adulthood $[26,27]$. The prevalence of overweight in children is an alarming public health problem that has been highlighted in recent decades. It is increasingly common to have children with pre-obesity and obesity, which causes an increased risk of complications related to nutritional status in adulthood [28]. The percentage of overweight in children varies greatly between countries and regions. In Europe, countries such as Greece, Italy, Spain, Malta and Portugal are those with the highest levels of overweight [29]. The prevalence of overweight (including obesity) observed in the children in this sample was worrying, making a total of $42 \%$, a number much higher than the last results made at the national level (31.6\%) [6]. As for differences between boys and girls, both the prevalence of pre-obesity and obesity were 
higher in boys, which can also be seen in other studies [30-32]. Several studies have attributed this worsening in the prevalence of overweight to the increased consumption of sugary drinks [3335], although others authors have not found a connection [10]. Due to the lack of a consensual definition of the term sugary drinks, there are disparities between studies regarding the drinks that are evaluated, which can influence the results.

A study carried out in 187 countries describes the countries of Central and Latin America as the biggest consumers of sugary drinks, while Asian countries, namely China, North Korea and Azerbaijan, have the lowest consumption levels. Despite the target population being adults, an age gradient was found, with younger adults being the biggest consumers of sugary drinks. The authors justify these results with the advertising and marketing behind the business of this product [36], aimed mainly at younger populations, in which children with very young ages, such as those in the present study, can also be inserted. Furthermore, it was reported that in Portugal, adolescents aged about 15 years old consumed soft drinks less frequently than children aged 11 [1]. Although the results of this study are not statistically significant, there was a trend with regard to consumption behaviour, related to certain drinks, and the prevalence of overweight. It was found that beverages such as soft drinks, among others, belonged to class 1 , with a lower frequency of consumption, which provided a protective effect on children being overweight. On the other hand, iced tea and fruit juices and nectars are associated with a frequency of weekly consumption (class 2), which seems to be associated with the group of children who are overweight. This consumption trend is not in agreement with the results observed in a study carried out in Canada, where the highest prevalence of overweight was associated with the group of drinks in which soft drinks (with and without gas), Coca-cola or Pepsi and soda were included [37]. However, our results are similar to a study carried out in 2013, in which children also consumed greater quantities of fruit juices compared to soft drinks [38], as well as other study carried out with children aged 2 to 5 years [39].

A possible explanation for the frequency of fruit and fruit consumption, such as iced tea, is higher than the frequency of drinks (with the exception of chocolate milk) is information regarding the effects of excessive consumption of carbonated drinks (such as carbonated, Coca-cola or Pepsi and gas sodas) is widely publicized by the scientific community in the population, while information is displayed in drinks as sums and nectars of less affected fruits. According to our knowledge, only another study was carried out in Portugal with the aim of verifying an association between the high consumption of sugary drinks and the prevalence of overweight in children. No association was found, which can be explained by the inclusion of all different types of sugary drinks in a group and the fact that portions of each drink ingested were not used to show any effect on the child's weight [40]. The present study has some limitations: a) application of the questionnaire using the self-filling method; b) lack of information about the participants' eating habits and lifestyles; c) geographic location of schools, as they are located in one of the municipalities with the greatest purchasing power in Portugal and where a large part of the inhabitants have a high degree of literacy. Thus, it is important that further studies are carried out in different regions of Portugal so that it is possible to better understand and characterize the possible relationship between the consumption of sugary and non-recommended beverages and the prevalence of excess weight in Portuguese children. The increase in the consumption of these drinks in children aged 6 to 9 years has been described worldwide [41], but the results are not yet conclusive, perhaps due to the different types of drinks included in this concept and / or the use of different criteria used To assess nutritional status and consumption of sugary drinks.

\section{CONCLUSION}

The prevalence of overweight (pre-obesity and obesity) was high in the sample studied. Although there were no statistically significant differences, it was possible to observe a trend regarding the consumption of sugary drinks and the nutritional status of children, with a greater probability of being overweight when they belong to the consumption class of iced tea, nectars and juice. Fruit up to once a week. The results of this study are contrary to the beliefs of the majority of the population that only considers carbonated non-alcoholic drinks, namely soft drinks, carbonated and Cocacola or Pepsi, among others, as sugary drinks that carry a greater risk for the prevalence of excess of weight. This study highlights the importance of assessing the nutritional status of school-age children and the need to develop programs and strategies for the prevention and treatment of overweight in children, as well as food education programs that inform parents and children about the effects excessive consumption of sugary drinks.

\section{REFERENCES}

1. Currie C, Roberts C, Morgan A, Smith R, Settertobulte W, et al. (2004) Young people's health in context Health behaviour in school aged children (HBSC) study: international report from the 2001/2002 survey. Organização Mundial de Saúde. Health Policy for Children and Adolescents (4): 110-119.

2. Ding W, Cheung WW, Mak RH (2015) Impact of obesity on kidney function and blood pressure in children. World Journal of Nephrology 4(2): 223-229.

3. Padez C, Fernandes T, Mourão I, Moreira P, Rosado V, et al. (2004) Prevalence of overweight and obesity in 7-9- year-old Portuguese children: Trends in body mass index from 1970-2002. American Journal of Human Biology, 16(6):670-678.

4. Rito AI, Carvalho MA, Ramos C, Breda J (2013) Program Obesity Zero (POZ) a community-based intervention to address overweight primaryschool children from five Portuguese municipalities. Public Health Nutrition 16(6): 10431051.

5. Oliveira A, Araújo J, Severo M, Correia D, Ramos E, etal. (2018) Prevalence of general and abdominal obesity in Portugal: comprehensive results from the National Food, nutrition and physical activity survey 20152016. British Medical Journal of Public Health 18(1): 614.

6. Rito AI, Graça P (2015) Childhood obesity surveillence iniciative: relatório COSI Portugal 2013. Instituto Nacional de Saúde Doutor Ricardo Jorge.

7. Morgen CM, Rokholm B, Brixval CS, Andersen CS, Andersen LG, et al. (2013) Trends in prevalence of overweight and obesity in danish Infants, children and Adolescents-Are we still on a plateau? PLOS ONE, 8(7): e69860.

8. Van Jaarsveld CHM, Gulliford MC (2015) Childhood obesity trends from primary care electronic health records in England between 1994 and 2013: population-based cohort study. Archives of Disease in Childhood, 100: 214-219.

9. DeBoer MD, Scharf RJ, Demmer RT (2013) Sugar-sweetened beverages and weight gain in 2- to 5-year-old children. Pediatrics 132(3): 413-420.

10. Johnson L, Mander AP, Jones LR, Emmett PM, Jebb SA, et al. (2007) Is sugar-sweetened beverage consumption associated with increased fatness in children? Nutrition 23(7-8): 557-563.

11. Slining MM, Mathias K, Popkin BM (2013) Trends in food and beverage sources among US children and adolescents: 1989-2010. J Acad Nutr and Diet 113(12): 1683-1694. 
12. Malik VS, Popkin BM, Bray GA (2010) Sugar-sweetened beverages and risk of metabolic syndrome and Type-2 Diabetes. Reviews/ Commentaries/ADA Statements 33(11): 2477-2481.

13. Bleich SN, Wang YC, Wang Y, Gortmaker SL (2009) Increasing consumption of sugar-sweetened beverages among US adults: 19881994 to 1999-2004. The American Journal of Clinical Nutrition 89(1): 372-381.

14. Malik VS, Schulze MB, Hu FB (2006) Intake of sugar-sweetened beverages and weight gain: a systematic review. The American Journal of Clinical Nutrition 84(2): 274288.

15. Popkin BM (2010) Patterns of beverage use across the lifecycle. Physiology and Behavior 100(1): 4-9.

16. Lott M, Callahan E, Duffy EW, Story M, Daniels S (2019) Healthy beverage consumption in early childhood: Recommendations from key national health and nutrition organizations. Technical Scientific Report. Healthy Eating Research, North Carolina, USA.

17. Duffey KJ, Huybrechts I, Mouratidou T, Libuda L, Kersting M (2012) Beverage consumption among European adolescents in the HELENA Study. Eur J Clin Nutr 66(2): 244-252.

18. Kosova EC, Auinger P, Bremer AA (2013) The relationships between sugar-sweetened beverage intake and cardiometabolic markers in young children. Journal of the Academy of Nutrition and Dietetics 113(2): 219-227.

19. Pan A, Malik VS, Hao T, Willett WC, Mozaffarian D, et al. (2013) Changes in water and beverage intake and long-term weight changes: results from three prospective cohort studies. International Journal of Obesity 37(10): 1378-1385.

20. Hasnain SR, Singer MR, Bradlee ML, Moore LL (2014) Beverage intake in early childhood and change in body fat from preschool to adolescence. Childhood Obesity 10(1): 42-49.

21. Katzmarzyk PT, Broyles ST, Champagne CM, Chaput JP, Fogelholm M, et al. (2016) Relationship between soft drink consumption and obesity in 911 Years old children in a multi-national study. Nutrients 8: 770.

22. Machado Rodrigues AM, Fernandes RA, Silva MR, Gama A, Mourão, et al. (2018) Overweight risk and food habits in Portuguese pre-school children. Journal of Epidemiology and Global Health 8(3-4): 106-109.

23. World Medical Association (2013) Declaration of Helsinki-ethical principles for medical research involving human subjects $-64^{\text {th }} \mathrm{WMA}$ general assembly.

24. Organização Mundial de Saúde (2000) Obesity: preventing and managing the global epidemic. Report of a WHO consultation. WHO Technical Report Series 894, Geneva, Switzerland, pp. 1-252.

25. Center for disease control prevention - About child \& teen BMI (2000) Consult Novembro 2015.

26. Whitaker RC, Pepe MS, Wright JA, Seidel KD, Dietz WH (1998) Early adiposity rebound and the risk of adult obesity. Pediatrics 101(3): e5.

27. Williams S, Davie G, Lam F (1999) Predicting BMI in young adults from childhood data using two approaches to modelling adiposity rebound.
International Journal of Obesity and Related Metabolic Disorders 23(4): 348-354.

28. Dietz WH (1998) Health consequences of obesity in youth: Childhood predictors of adult disease. Pediatrics 101(Supplement 2): 518-525.

29. Wijnhoven TMA, Van Raaij JMA, Sjöberg A, Eldin N, Yngve A, et al. (2014) WHO European childhood obesity surveillance initiative: School nutrition environment and body mass index in primary schools. International Journal of Environmental Research and Public Health 11: 11261-11285.

30. Bracale R, Milani L, Ferrara E, Balzaretti C, Valerio A, et al. (2013) Childhood obesity, overweight and underweight: a study in primary schools in Milan. Eating and Weight Disorders 18(2): 183-191.

31. Mocanu V (2013) Prevalence of overweight and obesity in urban elementary school children in Northeastern Romania: Its relationship with socioeconomic status and associated dietary and lifestyle factors. BioMed Research International.

32. Pizarro JV, Royo BM (2012) Prevalence of childhood obesity in Spain; National Health Survey 2006-2007. Nutrición Hospitalaria 27(1): 154160 .

33. Grimes CA, Riddel LJ, Campbell KJ, Nowson CA (2013) Dietary salt intake, Sugar-Sweetened Beverage consumption and obesity Risk. Pediatrics 131.

34. Pan L, Li R, Park S, Galuska DA, Sherry B, et al. (2014) A longitudinal analysis of sugar-sweetened beverage intake in infancy and obesity at 6 Years. Pediatrics 134: S29-S35.

35. Papandreou D, Andreou E, Heraclides A, Rousso I (2013) Is beverage intake related to overweight and obesity in school children? Hippokratia 17(1): 42-46.

36. Singh GM, Micha R, Khatibzadeh S, Shi P, Lim S, et al. (2015) Global, regional and national. Consumption of sugar-sweetened beverages, fruit juices and milk: A systematic assessment of beverage intake in 187 countries. PLOS ONE 58: 1-20.

37. Danyliw AD, Vatanparast H, Nikpartow N, Whiting SJ (2012) Beverage patterns among Canadian children and relationship to overweight and obesity. Appl Physiol Nutr Metab 37(5): 900-906.

38. Han E, Powell LM (2013) Consumption patterns of sugar sweetened beverages in the United States. J Acad Nutr Diet 113(1): 43-53.

39. Connor O, Yang TM, Nicklas TA (2006) Beverage intake among preschool children and its effect on weight status. Pediatrics 118(4).

40. Valente H, Teixeira V, Padrão P, Bessa M, Cordeiro T, et al. (2010) Sugar-sweetened beverage intake and overweight in children from a Mediterranean country. Public Health Nutrition 14(1): 127-132.

41. Dereńa K, Weghuberb D, Carolicj M, Thivele D, Frelutf ML, et al. (2019) Consumption of Sugar-sweetened beverages in paediatric age: A position paper of the European academy of paediatrics and the European childhood obesity group. Annals of Nutrition \& Metabolism 74: 296-302. 